Aneurisma venoso portal

\title{
Portal vein aneurysm
}

10.20960/angiologia.00406

$10 / 07 / 2022$ 


\section{Aneurisma venoso portal \\ Portal vein aneurysm}

Edgar Cárdenas Figueroa ${ }^{1,2}$, Juan Tacuri Quezada ${ }^{1,2}$, Ricardo Salazar Poveda ${ }^{1,2}$, Víctor Viteri Pérez ${ }^{1}$,

${ }^{1}$ Servicio de Cirugía Vascular. Hospital Carlos Andrade Marín. Quito, Ecuador. ${ }^{2}$ Pontificia Universidad Católica del Ecuador. Quito, Ecuador

Correspondencia: Edgar Cárdenas Figueroa. Hospital Carlos Andrade Marín. Av. Universitaria. 170103 Quito, Ecuador

e-mail: geoovanny26@hotmail.com

Recibido: 14/02/2022

Aceptado: 16/02/2022

\section{CASO CLÍNICO}

Presentamos el caso de un hombre de 65 años con antecedentes de cardiopatía isquémica, enfermedad renal crónica, hipertensión portal moderada y carcinomatosis peritoneal. Presenta clínica de dolor abdominal difuso moderado de un mes de evolución acompañado de ascitis de origen carcinomatoso. La ecografía Doppler reveló la dilatación portal con flujo continuo del carácter venoso sugestiva de aneurisma venoso (AVP). La angiotomografía de abdomen confirmó la presencia de una dilatación de 49,6 $\mathrm{mm} \times 41,13 \mathrm{~mm}$ de la vena porta, sin signos de trombosis, no accidentado, con extensión hacia las ramas portal derecha e izquierda (Fig. 1). Por el alto riesgo quirúrgico y las comorbilidades del paciente se determinó un tratamiento conservador y un seguimiento continuo. 


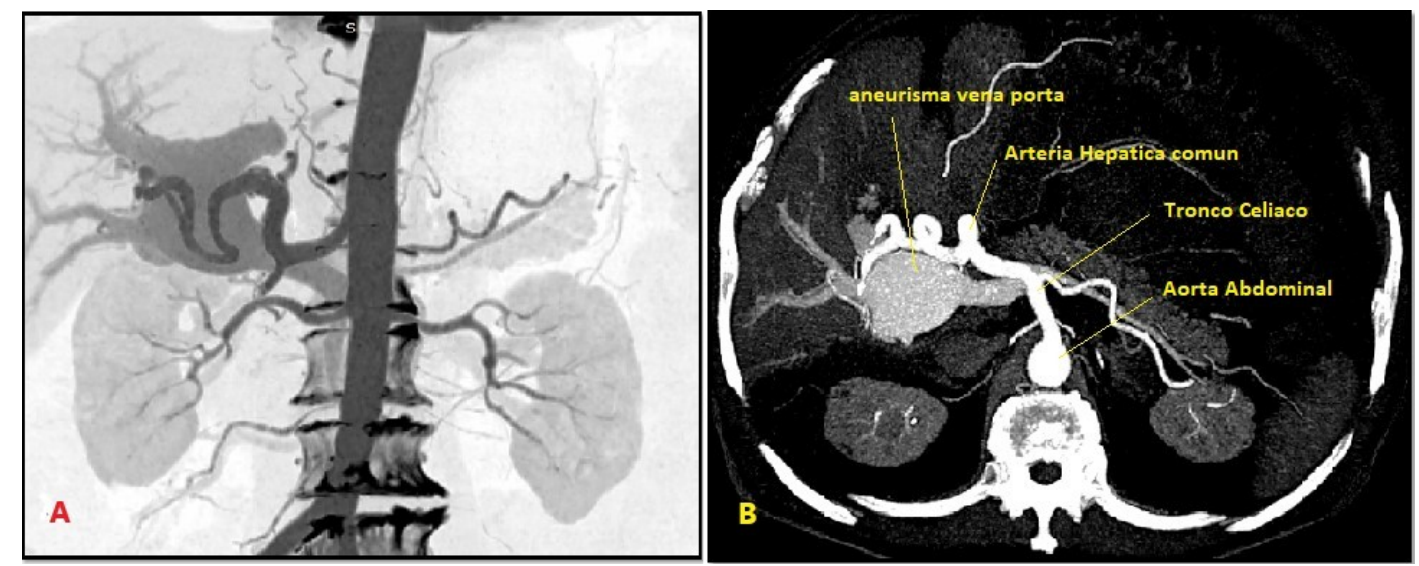

Figura 1. A. Corte coronal en negativo de AVP. B. Corte axial con descripción anatómica y relaciones de AVP.

\section{DISCUSIÓN}

Los AVP son infrecuentes: representan el 3\% de los aneurismas venosos, definidos cuando el diámetro de la vena porta es superior a $19 \mathrm{~mm}$ en pacientes cirróticos y de $15 \mathrm{~mm}$ en personas sanas (1). La incidencia es del 0,06\% (2). Su etiología puede ser congénita o secundaria a cirrosis, pancreatitis, traumatismos, antecedentes quirúrgicos e hipertensión portal, presente en la tercera parte de los aneurismas adquiridos, entre los que los de tipo extrahepáticos son los más frecuentes $(2,3)$. Su hallazgo generalmente es incidental y su clínica puede ir desde ser asintomáticos o debutar con dolor abdominal y hemorragia, con lo que se convierten en una emergencia (4).

El manejo de los AVP sigue siendo controvertido, con opciones que van desde la conducta expectante hasta la intervención quirúrgica, que estaría indicada, según la literatura, en casos sintomáticos y con diámetros superiores a $30 \mathrm{~mm}$. Se realizan resecciones en pacientes sin hepatopatía y shunts para aquellos con hipertensión portal y cirrosis (con una mortalidad del 40 \%) (1,2). Aunque el manejo no se ha estandarizado, según reportes de regresión espontánea de AVP consideramos que hay que manejar caso por caso según la clínica y las comorbilidades (5).

\section{BIBLIOGRAFÍA}


1. Tan RLW, Ng ZQ. Portal venous aneurysm. BMJ Case Rep 2021;14(7):e244704.

2. Hernando Sanz A, Navarro-Aguilar V, López-Andújar R. (2021). Portal vein aneurysm, an update on the subject. A case report. Rev Esp Enferm Dig 2021;113(1):77-8. DOI: 10.17235/reed.2020.6842/2019

3. Rana SS, Dhalaria L, Sharma R, Gupta R. Extra-hepatic portal vein aneurysm diagnosed by EUS. Endoscopic Ultrasound 2020;9(4)270-1. DOI: 10.4103/eus.eus_40_20

4. Priadko K, Romano M, Vitale LM, Niosi M, De Sio I. Asymptomatic portal vein aneurysm: Three case reports. World J Hepatol 2021;13(4):515-21. DOI: 10.4254/wjh.v13.i4.515

5. Watanabe Takase K, Okada K, Aikawa M, Okamoto K, Koyama I. Aneurisma de la vena porta con regresión espontánea completa a los 10 años con tratamiento conservador. Diario Clínico de Gastroenterología 2020;13(5):940-5. DOI: 10.1007/s12328-02001131-6 